\title{
Supply Chain Disruptions and Consumer Behavior Change from COVID-19: Empirical Evidence and Long-Term Implications for Supermarkets in the
} UK

\author{
Maaz Khan', Azzam Alroomi², Konstantinos Nikolopoulos ${ }^{3, *}$ \\ ${ }^{1}$ Alliance Manchester Business School, Manchester, Greater Manchester, UK. \\ ${ }^{2}$ Business Department, Arab Open University, Kuwait Ardiya, Kuwait. \\ ${ }^{3}$ Business Information Systems \& Analytics, Business School, Durham University, Durham, UK.
}

How to cite this paper: Maaz Khan, Azzam Alroomi, Konstantinos Nikolopoulos. (2022) Supply Chain Disruptions and Consumer Behavior Change from COVID-19: Empirical Evidence and Long-Term Implications for Supermarkets in the UK. Journal of Humanities, Arts and Social Science, 6(1), 28-42.

DOI: $10.26855 /$ jhass.2022.01.003

Received: November 25, 2021

Accepted: December 20, 2021

Published: January 19, 2022

*Corresponding author: Konstantinos Nikolopoulos, Business Information Systems \& Analytics, Business School, Durham University, Durham, UK.

Email: kostas.nikolopoulos@durham.ac.uk

\begin{abstract}
The COVID-19 pandemic has caused disruptions to supply chains and changes to consumer behaviours around the world. This research looks at those two aspects within supermarket retail chains in England between now and the time the first lockdown ended. It also explores the changes supermarket supply chains are making for the near future as a result of the pandemic. Both of these areas, to the best knowledge of the authors have not been covered so far in literature. The research followed a qualitative approach with interviews conducted of supply chain professionals and store managers belonging to large supermarket chains. A thematic analysis was performed revealing the main themes discussed in interviews. The results imply supply-side disruptions have been more significant than demand-side disruptions within the past year or so. Moreover, some indications are given regarding the recent developments supermarket chains are making for the future to be better equipped to handle any new lockdowns or pandemics. The research has informed theory and practice that supply-side issues are the bigger concern currently in England and has mentioned a few ways to manage them. Additionally, by introducing key developments for the future, the research has highlighted the importance for other grocery retailers to think of ways to transform their supply chain to not only withstand disruptions, but also compete in the grocery retail space in the longer-term.
\end{abstract}

Keywords

COVID-19, Pandemic, Supply Chain, Disruptions, Supermarkets

\section{Introduction}

The COVID-19 pandemic is unlike any other global healthcare crisis the world has seen and was called the most challenging since the Second World War by the UN chief, Antonio Guterres (Baynes, 2020). It spread across the globe from Wuhan, China and caused disruptions to many workplaces, economies and daily life in general. England saw its first case in January 2020 and a couple of months later in March, the disease was declared a global pandemic (Russell, 2021) (Who.int., 2020). At that time, lockdowns were enforced which led to the closure of most retail businesses, with grocery stores being a notable exception. Consequently, supply chains have been overbur- 
dened due to uncertainty in supply and skyrocketing demand. This has probably been the most apparent in supermarkets (Do et al., 2021). Normally, food supply chains are stable with a predictable demand, however lockdowns and fear of shortages led people to panic buy, with reports that weeks leading to the first lockdown saw an increase in UK grocery sales of $20 \%$. This was equivalent to a billion pounds worth of food being stockpiled (Davey, 2020). Despite pleas from major retail bodies (BBC.co.uk, 2020), the panic buying behaviour did not stop. Naturally, supply chains and suppliers did not anticipate this and were unable to respond, thus resulting in temporary shortages.

Many previous researches have looked at supply chain disruptions during COVID-19 such as Hobbs (2020), Bentall et al. (2021), Leng (2021), Guan et al. (2020) and several others. However, all of these focused on disruptions during the initial outbreak and to my knowledge there have not been many researches that looked at the state of disruptions after that, particularly within England. As of September 2021, England has had 2 different waves (Ons.gov.uk., 2021) and 3 different national lockdowns (Baker et al., 2021). Therefore, the aim of this research is to look at disruptions in England, from the second lockdown until now to see how they've evolved since the first lockdown. The second aim which was also not covered well in past literature is to look at the long-term supply chain changes in England as a result of the pandemic. Most supply chain related changes mentioned were in the past year and a half when the pandemic situation was more severe and hence were applicable for that moment in time, but perhaps not so much now. Both aims only focus on supermarket retail chains and no other type of business. Hence the two research questions proposed are:

\section{$>$ RQ1: How did disruptions and consumer behaviours evolve after the initial (March 2020) lockdown? \\ $>$ RQ2: What are the longer-term supply chain related changes as a result of COVID-19?}

This research contributes to literature by filling in the gaps highlighted above and looking at the biggest issues and changes after the first lockdown. Furthermore, it takes a glance into the future to look at what developments or changes supermarkets feel will occur to supply chains in the longer-term. It will hopefully bring new insights as to how supply chains will transform in the near future. The practical implications are more important here. RQ1 will enable chains to compare the experiences of each other and analyze if others 'were in the same boat' or not. And if they were not, they can assess why disruptions they faced were less or more severe than their competitors. RQ2 is even more important, because by understanding the future advancements other chains are working towards, the chains lagging behind can get up to speed to compete in the longer-term. Interviews were conducted to carry out this research and gain qualitative insights into the perspectives of supermarket chains.

\section{Literature Review}

A disruption, according to Schmidt and Raman (2012) is 'an unplanned event that adversely affects a firm's normal operations.' Therefore, events like political tensions, natural disasters, pandemics can all be the source of disruptions. The COVID-19 pandemic is an example of a global disruption which caused workplaces and organizations around the world to shut down and work from home. One of the exceptions was the food supply chains and distribution systems where a lot of the tasks are completed on-site (de Paulo Farias \& dos Santos Gomes, 2020). During the initial stages of the pandemic, these were severely strained by the high pressure caused by several factors such as the increase in demand for supermarket retail products, the increased panic buying and hoarding behaviours, the disruptions in transportation routes, tighter trade restrictions, labour shortages, and stricter lockdowns and social distancing rules (Hobbs, 2020). Although, there was a temporary shortage (Deaton \& Deaton, 2020) countries quickly moved to reassure people that adequate supply was available (Reiley, 2020) (BBC.co.uk., 2020).

\subsection{Demand-side disruptions}

Multiple researches have detailed the reasons for supply chain disruptions faced by the retail food industry during COVID-19. Hobbs J. (2020) explained these can be due to either demand-side shocks or supply-side shocks. The demand-side shocks are what this literature review mainly focusses on due to Cranfield J. (2020) predicting them as being the bigger driver of disruptions. The first major demand-side factor is the change in consumer behaviours. Both articles discuss the sudden shift in demand from the foodservice sector (cafes, bars, restaurants) to the food retail sector. Closures in the foodservice sector due to 'work from home' orders' caused 30\% of UK's food consumption to move to supermarkets which resulted in additional burden on supermarket supply chains (Davey, 2021). J. Hobbs (2020) mentions that the foodservice sector supply chains were unable to assist in overcoming this 
burden as they did not possess the distribution infrastructure and the ability to create smaller packaging ideal for home use.

Traditionally, as Zarei et al. (2011) stated, food supply chains have had a predictable demand with just-in-time and lean strategies being dominant. The lean strategy emphasizes on minimizing costs and inventory levels which means sacrificing service levels that come with a resilient and agile supply chain (Carvalho et al., 2011). Similarly, just-in-time also focuses on being efficient which makes both suitable in normal times. However, the COVID-19 pandemic has exposed the flaws of this system as it experienced tremendous disruptions from demand and supply-side shocks. Because of the low storage and distribution abilities of the modern food retail supply chains, they have failed to meet the spike in market demand during the current crisis (Garnett et al., 2020) (Islam et al., 2021). Furthermore, some online newspapers also highlighted the change in consumer behaviour to a smaller, more basic range of products (Reiley, 2020; Baum \& Robertson, 2020) left supermarkets overwhelmed as they switched from producing a high variety of items to only a few popular ones.

J. Hobbs (2020)'s second popular factor for demand-side shocks is the panic buying or hoarding behaviour which saw various essentials and key items such as toilet paper, pasta, rice, hand sanitizers, soaps and canned food simply being swept off supermarket shelves by shoppers. Panic buying is a common occurrence in disasters such as pandemics because of the disruption to the supply of goods and services (Badgaiyan \& Verma, 2015; Wu et al., 2021). Previous research suggests panic buying is caused by fear rather than actual food shortages (Islam et al., 2021; Tsao et al., 2019). The fear could be that supplies will run out hence customers stockpile as an insurance policy or the fear of the pandemic itself, where exposure to people is minimized by reducing the number of shopping trips and buying more items in each trip (Cranfield, 2020). Moreover, as discussed by the research of (Leung et al., 2021), social distancing measures along with shortened store opening hours also add to anxiety, for which panic buying becomes a source of comfort. This places additional load on supermarkets, and many reported to not being able to fulfil customer demand in times of strict social distancing (Davey, 2021). Additionally, research shows as the number of cases rose, governments imposed lockdowns which further aggravated panic buying and supply chain disruptions (Hobbs, 2020). During lockdowns, the lack of public trust in governmental decisions and the fear of total shutdown of retail stores led to increased stockpiling (Leng, 2021).

Multiple researches have studied lockdowns in regards to their timing (Bentall, 2021; Nikolopoulos, 2021), their strictness and length (Guan, 2020; de Paulo Farias \& dos Santos Gomes, 2020). The articles found the earlier the lockdown was imposed, the higher the over-purchasing behaviours and that supply chain losses were affected more by the duration of lockdowns than their strictness. Generally, it can be concluded earlier, stricter and shorter lockdowns are beneficial, however this requires global coordination which can sometimes prove to be tricky. Finally, the literature also points out to the fact that information shared on TV and social media in the form of pictures and videos of empty supermarket shelves creates more panic that leads customers to buy obsessively (Depoux et al., 2020). Social media consumption during the pandemic had soared to keep in touch with friends and family whilst in lockdown and to be updated with news about the pandemic. Watson A. (2020) found that $40 \%$ of online users used social media excessively and previous studies have shown that the dissemination of scarcity messages intensifies the urge to buy (Liu et al., 2016; Luqman et al., 2020).

\subsection{Supply-side disruptions}

Supply side disruptions mentioned by Hobbs J. (2020) include labour shortages, disruptions to supply and transportation networks and the closure of borders between countries. The drastic rise in demand experienced during COVID-19 was difficult for supermarkets to match using their existing workforce. Hence many of UK's biggest supermarkets hired additional staff to assist them in the challenging situation (Speare-Cole, 2020). Moreover, Hobbs J. (2020) says labour shortage can also occur because of a decrease in the existing number of employees due to illness, self-isolation and movement restrictions. Next, the disruption to transportation networks and the closure of borders has made trade between countries quite difficult. Supply chains these days are quite global, this includes the UK too as it gets almost half of its food supply from overseas, especially from Europe (Gov.uk., 2021a). Therefore, the dependance on smoothly running transport networks is essential and strict inspection at borders makes it much harder for supermarkets to keep up with high surges in demand.

\subsection{Tackling disruptions}

A wide variety of methods have been suggested in the literature for minimizing or managing disruptions. Some 
of these have already been employed by firms during COVID-19. One such method is rationing where purchase limits were set to key essentials to allow shoppers to only buy a maximum of 2-3 of each item (Speare-Cole, 2020). This can be really effective to prevent the hoarding behaviour of consumers, while suppliers of supermarkets ramp up production to meet the growing demand. Another possible method could be sharing of resources between competitors. While this may seem unacceptable to some as competitors normally do not share resources in normal times, however during times of crisis sharing resources has been found to be quite effective and efficient for companies. One such example has been seen in the pharmaceutical industry where GSK has partnered with its competitor Sanofi in the fight against Covid-19 to develop a vaccine (FT.com., 2020). Therefore, the coopetition between firms to develop complementary products and share resources does need to be given some thought.

While mentioning about collaboration between firms, it is also important to consider collaboration between a firm and its suppliers. Matopoulos et al. (2019) characterized buyer-supplier relationships in the retail food industry as 'relationship failure'. They explained how such relationships only remain limited to transactions and fail to develop into collaborative, supportive relationships which will be beneficial during times of crisis. This means during a pandemic both parties will come to each other's rescue by sharing risks, costs and assisting each other to function smoothly. Such relationships also enable firms to build supply chain resilience and flexibility which means they'll be able to adjust better when abrupt changes or disruptions occur in demand and/or supply (Hobbs, 2020). One of the ways to build resilience is to improve supply chain agility (Nandi et al., 2021). As mentioned earlier, supply chains are usually built on lean principles which enable firms to drive down costs. However, agility allows firms to be more responsive, thus improving customer service levels. Hence, the tradeoff between cost minimization using lean, versus responsiveness or resilience using agility would need to be assessed. There is ample evidence however, of agility being more effective than long term plans or flexibility in managing disruption related effects (Shekarian et al., 2020).

Other changes suggested are for grocery retailers to move parts of their businesses online, particularly seeing the rise in online grocery shopping during the pandemic and with such behaviours expected to become permanent even after the pandemic ends (Do et al., 2021). Moreover, having mentioned the rise of social media use during Covid-19 governments, local authorities and supermarkets could use social media to spread reassuring messages and campaigns that help tackle anxiety and panic buying (Leung et al., 2021). A useful idea would be to ask celebrities to spread the word as people are quite likely to listen to them. Finally, there was a suggestion to diversify supply sources, arrange backup suppliers and work with more regional and local suppliers (Leng, 2021). While the latter two options could be considered, the first one about diversifying sources was not considered appropriate by Leung et al. (2021). The reason explained by the authors is that the pandemic is a global one and almost all suppliers face the same situation so sourcing from alternate options may not make any real difference.

\subsection{Forecasting COVID-19 growth rates}

Having discussed above how increasing cases of COVID-19 can lead to a rise in stockpiling behaviours, forecasting the number of cases becomes essential for demand management and supply chain planning at firm level. Moreover, what was also discussed was the timing of lockdowns, as this can affect panic buying. Hence, forecasts also become important from a government's decision-making point of view (Nikolopoulos et al., 2021). However, there are difficulties with pandemic forecasts. Petropoulos and Makridakis (2020) mention there needs to be sufficient historical data which is reliable but still forecasts may not be true as history rarely repeats itself. Furthermore, countries vary in their structure and manage the pandemic in different ways to each other which affects the accuracy of forecasting models. The level of reporting, number of tests, governmental policies and healthcare systems are all different between countries, thus making the forecasting task more complex (Nikolopoulos et al., 2021).

\subsection{Techniques used for forecasting}

There have been a wide variety of techniques used for forecasting the growth of the pandemic. These include basic but powerful ones like simple time series models and extracting current and past trends which were then extrapolated (Petropoulos \& Makridakis, 2020; Doornik et al., 2020). They assumed trends will apply indefinitely and no convergence was assumed. The former paper also accounted for the uncertainty in data with the belief that it was important for decision making in such high-risk cases. Another popular model used was Autoregressive Integrated Moving Average (ARIMA) as in the case of (Alzahrani et al., 2020) and (Kumar et al., 2020). While these yielded good results in the short term, Feroze (2020) found the Bayesian structural time series (BSTS) models to outperform the ARIMA models in terms of accuracy. This maybe because ARIMA models are linear and high nonlinear- 
ity decreases accuracy. The author further went onto state the effectiveness of BSTS models in planning and prioritizing. And just like Petropoulos and Makridakis (2020), they factored in uncertainty as well because data collected was in the very early stages of the pandemic.

However, one of the most recent and comprehensive papers on different types of forecasts for COVID-19 has been that of Nikolopoulos et al. (2021). It evaluated different methods for forecasting the evolution of a pandemic and used the data of five countries to achieve generalizable results that could be applicable worldwide. A number of different methods were used, and it was found that different models performed better in different countries. There are other models too which have been less common in literature such as different kinds of regression and autoregression methods (Schorfheide \& Song, 2020; Sujath et al., 2020). Then there are Gompertz curves (Mazurek et al., 2020) and a new model called Susceptible-Exposed-Symptomatic Infectious-Asymptomatic Infectious-Quarantined-Hospitalized-Recovered-Dead (SEIDIUQHRD), both of which make accurate short-term predictions (Nabi, 2020). However, these models have not been used as much as the other popular ones in the paragraph above.

\subsection{Forecasting product demand}

Forecasts for the evolution of COVID-19 can enable us to estimate excess product demand during the pandemic (Nikolopoulos et al., 2021). As mentioned previously, the more COVID-19 spreads, fear in people rises which increases stockpiling behaviours. Therefore, it is quite logical that the importance of forecasting product demand increases during a disruption like COVID-19. K. Nikolopoulos (2021) suggested the intermittent demand forecasting approach for events with high uncertainty and high unpredictability, i.e., black swan events (Taleb, 2007). While COVID-19 is classed as such an event, it did not show intermittent behaviour in many industries, especially supermarkets. Therefore, this technique does not seem applicable here. There was however, a forecasting exercise done in a recent paper by Nikolopoulos et al. (2021). It outlined important information for governments such as the timing and length of lockdowns and how it affected product demand. Furthermore, it advised to obtain safety stocks and consider rationing to be prepared for the worst situations.

While the paper offers plenty of insight, it was completed in the early stages of the pandemic with supply and demand data being unavailable. As a result, the authors decided to use Google trends to estimate the demand change for products in four sectors. Now, almost a year later, actual data can be used which may yield better results in forecasting. Finally, forecasting supply is just as crucial as forecasting demand in a situation where there is high uncertainty for both (Syntetos et al., 2016). Paragraphs earlier mention of supply-side shocks such as delayed deliveries due to problems in transport networks and suppliers not being able to match production with the demand spike. Managing supply is essential in resolving these problems and the article highlights a gap in this area currently.

\section{Context}

The topic of forecasting fits more into the field of operational research rather than operations and supply chain management. However, forecasting and planning is needed for various operational and supply chain related activities like inventory control, transportation, and production (Spithourakis et al., 2011). Forecasting helps understand demand and supply needs that may fluctuate enormously in a black swan event like COVID-19. Nikolopoulos et al. (2020) explain these are further affected by governmental decisions such as lockdowns. Governments use another set of forecasts, i.e., the forecasts for the evolution of COVID-19 to impose policies that curb the spread of the virus (Choi, 2021). For supermarket supply chain managers, it is essential to understand how this can impact them. It is well known how demand soared during lockdowns (Davey, 2020) and this has an adverse effect on supply chain performance in the form of higher costs to inventory, supply and transportation (Abolghasemi, 2020). Therefore, forecasting becomes more significant in such cases to reduce ambiguity that affects supply chain decision making (Gunessee \& Subramanian, 2020).

As discussed earlier, supply chains experienced demand and supply disruptions during the pandemic with panic buying seen across supermarkets whilst in lockdown. Without information on how long lockdowns would last, customers feared the worst and started to bulk buy to stock long lasting items at home. The impact of this behaviour extended to central warehouses depleting the additional stock and burdening logistics capacity (Saarinen et al., 2020). Knowledge of the current and previous pandemics tells us lockdowns make agricultural production increa- 
singly difficult due to misallocation, inefficiencies and labour shortage (Zhang et al., 2020). This is a major reason why suppliers could not ramp up production to meet the demand surge. Moreover, the bullwhip effect caused by distorted order information upstream (Lee et al., 1997) made inefficiencies worse. The downstream unit would usually over specify their supply requirements to avoid supply shortages making demand even more unpredictable. To make it worse, the closure of borders, increased checks and disruptions to transportation routes made haulage more costly and the delivery of supplies very unreliable (Zhu et al., 2020).

Therefore, to minimize losses caused by supply and demand mismatches forecasting became increasingly important during the pandemic. Forecasting helps understand changing consumer demand patterns and market dynamics which enables food suppliers and retailers to make better judgements on retail inventory replenishments (Syntetos et al., 2016; Queiroz et al., 2020).

\section{Methodology}

This research was carried out qualitatively to obtain more rich descriptions of a new, unexpected event like Covid-19. A total of 10 interviews of store managers and supply chain professionals of 6 different major supermarket retail chains were conducted throughout the month of August. These were evenly split between large format supermarkets and convenience stores to get a reasonably good mixture and explore differences in the experiences supermarkets had during the pandemic. A combination of supply chain professionals and store managers was chosen because the former would look at the situation from a corporate viewpoint and provide a more high-level, broad understanding of stores across regions. In contrast, the latter would give a more detailed ground level opinion of the events that occurred. Most interviewees were found via LinkedIn, but a few were confirmed after visiting stores in the local area. All interviews were conducted either in person or using Zoom software and followed a structured interview approach lasting a maximum of 25 minutes. Each interviewee was informed the information provided would be anonymized and permission was taken for recording. Taking the research questions mentioned in the 'Introduction' section, further sub-questions were created for interviews. RQ1, which explores how consumer behaviours and disruptions changed had 4 sub-questions and RQ2 which looks at long term supply chain related changes to manage future pandemic related disruptions had 4 sub-questions too. All sub-questions are listed below.

$>$ RQ1a: England has had three different lockdowns. In terms of disruptions, were the latter two worse or better than the first one? Why so?

RQ1b: Have customer preferences changed during the pandemic to cheaper or more value for money products, such as buying the supermarket's own brand rather than other slightly more expensive brands?

$>$ RQ1c: Items like pasta, toilet rolls, sanitizers saw a sharp increase in demand during lockdowns. For which products did demand reduce? Has demand now returned to normal?

DQ1d: Are supermarkets still making mid to long-term forecasts considering how unpredictable Covid-19 spread, disruptions and timings of lockdown have been? If yes, then why?

$>$ RQ2a: Traditionally supermarkets have used lean \& JIT systems which have served well in reducing inventory and cost, but during the pandemic such supply chains struggle to keep up with the demand surge. Are there thoughts to increase agility/ responsiveness of the supply chain? If so, how?

$>$ RQ2b: Supply side disruptions include labour shortages, delayed deliveries due to disruptions in transportation networks and suppliers not being able to ramp up production to meet the demand spike. How can supply side disruptions be mitigated for future lockdowns/ pandemics?

$>$ RQ2c: How has COVID-19 changed the way demand and supply forecasting would be done in the near future?

$>$ RQ2d: Any other notable long-term changes to supply chain and logistics we have not discussed?

RQ1a aimed to compare the extent of disruptions experienced in the second and third lockdown to the first one knowing England has so far had 3 different national lockdowns (Baker et al., 2021). RQ1b analyzed if consumers have become more price conscious during the pandemic because of loss of jobs and a global recession. The next sub-question was formed because past literature only looked at items which experienced demand spikes. However, the items for which demand dropped during the pandemic are not known very well and RQ1c aimed to explore just that. Additionally, RQ1d investigated if supermarkets thought there was still a point in making mid-long term fore- 
casts given the unpredictability of the pandemic and any plans they made could turn out to be pointless in the near future. One of the points mentioned in 'Literature review' was the difficulties JIT and lean systems faced during the pandemic. Hence RQ2a analyzed if supermarkets were considering a move away from this system to a more responsive one to meet demand better. One aspect past literature covered well was how to manage demand-side shocks such as panic buying but limited information on managing supply-side shocks was found which led to the formation of RQ2b. RQ2c had an element of operational research by looking at how forecasting would change in the long-term because of COVID-19. Finally, RQ2d was an opportunity for interviewees to mention any other significant long-term changes to supply chain and logistics they had not been able to speak about in prior questions.

\section{Results}

To analyze interviews, a thematic analysis was conducted which identified different themes that best answered research questions. Firstly, the interviews were transcribed after which codes were made based on different categories found in the transcripts. This was an iterative process done about 3 times and each time more codes were made. To reduce complexity with the high number of codes, these were grouped further, and repetitions were eliminated. In the end, four notable themes came up which are presented in Table 1. The table mentions these themes with quotes from interviewees as illustrative evidence. Letters before the quote denote which interviewee the quote is from. For example, the first quote is from Interviewee B, second from interviewee $F$ and so on. There were 10 total interviewees (A-J). Finally, a third column provides my own interpretation about the quote and gives more context around it. Although some themes had more quotes than those listed in the table, due to the word limit only the best quotes were selected. Additional quotes around the themes can be found in Appendix A.

\section{Discussion}

The research aims to look beyond the first COVID-19 lockdown in England and explore supply chain related impacts in English supermarket chains because of the pandemic. More specifically, it firstly looks at supply chain disruptions and consumer behaviours from the second lockdown till now, because most available literature covers the first lockdown only. The first research question RQ1 would answer this. Secondly, this research also aims to keep an eye on the future developments or changes that would occur to supply chains in the longer-term. For this purpose, there is research question 2 (RQ2). For RQ1, the results show consumer demand for 'food on the go' and ready-made meals declined massively and stayed that way even after the first lockdown. This makes sense because of work from home orders, where consumers were now far away from any convenience stores where they could grab a quick bite like they do at work. Being at home also meant people had more time, so they'd cook more often whereas busy office routines pre-pandemic gave workers little time to prepare their own meals. Thirdly, because this was a health crisis, people were perhaps more health conscious and switched to fresher and healthier choices. This explains why demand for snacks, which are often unhealthy, fell. Finally, because the general behavior was stockpiling, it made no sense to go for ready-made meals like packed sandwiches which only last a few days. That is why items hoarded were long lasting ones like pasta, rice etc (Hobbs, 2020).

Another change in consumer behaviour has been the grocery shopping patterns as stated by interviewee I. More people shop on the weekdays than the weekends. The explanation for this could be once again related to working from home. For example, before the pandemic for a 9AM start many employees would have to wake up an hour earlier to get to work on time. However, now in the past year and a half they do not have to make that journey to work and can instead use that time for groceries. Also, because they are at home, they can get groceries delivered on weekdays using online shopping. In pre-pandemic times, the only option was the weekends as no one would've been home on the weekdays to receive the delivery.

Regarding disruptions, the supply-side ones have been more significant. Besides COVID-19, UK has also dealt with Brexit which has resulted in a shortage of drivers and unreliable deliveries. Section 2 mentioned UK's high proportion of food imports from Europe, and this along number of European workers in UK has impacted disruptions to an extent that it was the most discussed theme across all 10 interviews. Due to Brexit laws, working in the UK has become more complicated for EU workers and has led to labour shortage for supermarket chains. This occurrence agrees with previous research which had predicted this long before (Doherty, 2016; Hendry et al., 2019). Perhaps one way to counter such disruptions in supply, as interviewee E mentioned is to have products delivered quicker using rail instead of road transport. Another sub-theme discovered within supply-side issues was that su- 
permarkets couldn't fulfill demand using their preferred suppliers. Hence, they had to be flexible in searching for alternatives to avoid delays. With this, key findings in both consumer behaviours and supply chain disruptions from the second lockdown till now have been discussed and RQ1 has been answered.

For RQ2, the first major theme was around cutting costs and ranges. This feeds into the lean strategy of reducing waste (Charron et al., 2014) by prioritizing the best-selling items and agrees with literature such as (Shih, 2020) on minimizing product varieties to improve supply chain efficiency. Trimming down waste also lowers costs to the supply chain and the findings indicate that supermarkets are strongly emphasizing on this going into the future. The interviewees felt that by reducing ranges they would not only reduce the needless inventory they hold (which is another form of cost), but they would be able to get their suppliers focus more on the key items and improve the guarantee of them being delivered on a consistent basis.

Finally, the last theme of both RQ2 and the research in general are the developments within supply chains for the near future. A rather interesting point is the emergence of dark stores also called fulfillment centres. With online shopping becoming more popular during the pandemic, dark stores are being considered to complete customer orders and get them delivered quicker. These are similar to conventional supermarkets except customers are not allowed inside which makes it easier and faster for supermarket staff to go around the store and pick items required in online orders (Morgan, 2020). The second point within this theme is the realization of the benefits collaboration and information sharing can bring. Matopoulos et al. (2019) previously mentioned buyer-supplier relationships need to transform beyond transactions to improve supply chain performance and it seems there'd be more cooperation in the future. Sharing information, especially regarding forecasting is closely linked as this also would minimize uncertainties in supply and demand (McCarthy \& Golicic, 2002).

\subsection{Theoretical contributions}

This research contributes towards theory in many ways. Firstly, it addresses the gap found in literature of the least demanded items during the pandemic. Most researches, as illustrated in the 'Literature review' section, only highlighted the popular products during the pandemic but failed to cover the ones for whom sales fell. Secondly and more important, this research indicates supply-side issues were greater than demand during the pandemic, especially with interviewee I explicitly stating this. This may seem contradictory to Cranfield J. (2020)'s point mentioned in section 2.1, however, that research was done very early in the first wave of the pandemic and the situation has changed a lot since then, with panic buying significantly less than it was in the first lockdown. Moreover, the author's point was just a prediction and not a well-researched fact. Additionally, it could also be caused by Brexit, the laws for which did not come into plan then. Brexit has certainly exacerbated supply-side shocks.

This research also strengthens the suggestion of previous research like H. K. Leng (2021) and Islam et al. (2021) about sourcing from alternative suppliers in times of crisis and diversifying the supplier base. Such a move would increase resilience and responsiveness of the supply chain and enable it to fulfill demand better in case a certain supplier is short of a key product (Fiksel et al., 2015). Furthermore, although the 'Literature Review' section discussed about the difficulties supply chains faced during COVID-19 due to their lean and just-in-time systems, it seems there are not many plans to make it more responsive other than by working with more suppliers. It could be because the pandemic is not as severe as it was before with deaths significantly lower (Gov.uk., 2021b) than the time those journal articles were written. People and supply chains have adjusted since then. Additionally, supermarkets can't get more responsive by holding more inventory for example. Many products like fruits, vegetables, chilled food, and dairy go out of date quickly. In summary, the focus is still on cutting down costs and making operations leaner. For instance, there is more of a move towards reducing variety to increase resiliency and this follows recommendations given by Capgemini (2021).

Finally, the research also adds to literature that the forecasting process from now would involve greater collaboration between supermarkets and their suppliers. Having different entities, partners and decision-making units work together can enable better decisions to be made under ambiguity (Gunessee \& Subramanian, 2020). As Lee et al. (2000) mentioned, sharing forecasting information whereby a supermarket may send its demand forecast along with order quantity to its supplier, would enable better tracking of the changing demand and improve the forecasting accuracy.

\subsection{Practical contributions}

There are several contributions of this research towards practice too. The first one is that supermarkets should start exploring and building relationships with other suppliers to be ready for any abrupt disruptions in the future. 
Especially for England and in fact all of UK suppliers it makes more sense with Brexit laws being passed. There would be more taxes, duties, and charges for products imported from the EU into the UK (Lang \& McKee, 2018). With the UK getting a large proportion of its food supplies from Europe (Gov.uk., 2021a), things could become more challenging unless there is a move towards working with more local and regional suppliers. Hence Brexit should be taken as an opportunity by supermarket managers to work with local farmers and agricultural firms to produce more locally. This benefits supermarket chains in numerous ways such as increasing turnaround time and supply chain resilience, the latter being vital for recovery (Elluru et al., 2017; Ivanov \& Dolgui, 2018). Supermarkets may also consider reducing the range of products within stores to increase responsiveness and hence resilience.

Another supply related problem in my findings was the shortage of drivers which leads to less reliable deliveries. Although 8/10 interviewees mentioned driver issues, only 2 spoke about how they're trying to resolve them, and both were from the same supermarket chain. Therefore, it is not known what other chains are doing, but they can also certainly look at providing greater incentives and benefits to get more driver applications from the local population. It would make deliveries more consistent and lead to higher customer satisfaction, an important aspect for supermarkets. Moreover, as also mentioned by (Accenture.com. 2020), supermarket chains should look to engage all relevant functional teams and external parties in forecasting as a collective group. This will prevent any inconsistencies they'd usually have when forecasting individually and will manage supply and demand better. Finally, and although only gaining popularity recently, supermarkets can consider dark stores as an innovative way to complete online orders quicker. With the increase in online groceries in COVID-19 and the situation looking set to stay that way (Do et al., 2021), a lot of the burden can be removed from conventional stores and its staff by shifting this demand to dark stores.

\subsection{Limitations and future research}

Although this research answered both research questions, there are several limitations that have been identified. The first is that only those supermarkets were studied which have a chain of stores all around England and the UK. These are all the large supermarket retailers with names known to everyone. It would also have been useful to also interview private stores which sell products specific to certain regions of the world like South-Asian stores, Middle-Eastern stores, Far-East Asian stores. All these smaller supermarkets experienced disruptions due to the pandemic too and it would have been interesting to see how their experiences compared to larger supermarket chains. Upon approaching them with interview requests, we were told they were short staffed and could not spare time. A possible reason is because this research was conducted in the summer and interviews taken in August, when the bank holiday falls. Many people including supermarket staff go on vacations leaving lesser number of potential interviewees. Therefore, this is one area of possible research for the future.

Secondly, this research was only done in England and not even the entire UK which makes results less generalizable to other parts of the world. No other country has faced Brexit for example, which is perhaps why supply-side issues were more significant here. It would be useful to firstly extend this research to other countries within UK-Scotland Northern Ireland and Wales to see if they had the same problems too, particularly on the supply-side. Common sense says they probably would have, which is why my research nevertheless is still relevant. Next, the study could be extended to other countries outside the UK to establish comparisons. Additionally, more interviews can be conducted to develop solid grounded theory which was not possible due to the time constraints and the limited number of interviews we took. Finally, little research has been published online about dark stores. More of this could be done to see if they are a viable option for supermarket chains post pandemic. Important questions could be answered like the supply chain and operational changes needed to incorporate dark stores alongside conventional stores within a supermarket’s business.

\section{Conclusion}

This research aimed for two things. Firstly, it looked at consumer behaviours and the state of disruptions to supermarket supply chains in England, from the point the first lockdown ended until the current time to analyze the most common challenges faced. Secondly, it explored any changes or developments supply chains would be making to their existing operations in the near future. Being a qualitative study, it used interviews with store managers and supply chain professionals to obtain relevant information. Based on the analysis of findings, it appeared that supply-side issues were more dominant, particularly in the most recent times. This went against the prediction made 
by Cranfield J. (2020) about a year and a half ago. However, it was not a surprise because England and in fact all of UK have faced the shock of Brexit along with COVID-19. Regarding the second aim, supermarket chains are looking to lower costs and streamline their operations for the future by reducing product portfolio and the ranges they carry. Moreover, they have also begun to implement some new and rather interesting changes. The first one being dark stores which will be warehouses acting as fulfillment centres to improve the customer online grocery shopping experience by completing and delivering their orders quicker. The second is more information would be shared with suppliers and collaboration would be increased to manage disruptions better.

This research adds to evidence of previous research about sourcing alternative products during times of crisis. Additionally, it informs literature that supply-side issues have been more significant than demand lately and that minimizing costs and inventory is the goal for the future. For practice, it encourages supermarkets to broaden their supplier base and increase benefits for vehicle drivers, the shortage of which has been the most talked about problem. Overall, some useful findings have been discovered which primarily cover the supply-side shocks and ways to mitigate them. This was a gap found in the review of previous literature. To better understand the implications of these results the study could be conducted for a larger number of interviewees and extended to other parts of the UK which may have also experienced similar shocks due to the combination of Brexit and COVID-19. It could then be conducted outside the UK to compare challenges faced between different countries.

\section{References}

Accenture.com. (2020). COVID-19: Boost Agility and Responsiveness with Supply Chain Planning | Accenture. [online] Available at: <https://www.accenture.com/be-en/insights/consulting/coronavirus-boost-agility-responsivenesssupply-chain-planning $>$ [Accessed 6 September 2021].

Alzahrani, S., Aljamaan, I., and Al-Fakih, E. (2020). Forecasting the spread of the COVID-19 pandemic in Saudi Arabia using ARIMA prediction model under current public health interventions. Journal of Infection and Public Health, 13(7), pp. 914-919.

Badgaiyan, A. and Verma, A. (2015). Does urge to buy impulsively differ from impulsive buying behaviour? Assessing the impact of situational factors. Journal of Retailing and Consumer Services, 22, pp. 145-157.

Baker, C., Kirk-Wade, E., Brown, J., and Barber, S. (2021). Coronavirus: A history of English lockdown laws. [online] House of Commons Library. Available at: <https://commonslibrary.parliament.uk/research-briefings/cbp-9068/> [Accessed 5 September 2021].

Baum, K. and Robertson, S. (2020). Food makers shift production to focus on the basics during COVID-19 pandemic. [online] The Globe And Mail. Available at: <https:/www.theglobeandmail.com/business/articlefood-producers-move-to-make-just-the-basics/> [Accessed 5 September 2021].

Baynes, C. (2020). Coronavirus pandemic worst crisis since Second World War, says UN chief. [online] The Independent. Available at: <https:/www.independent.co.uk/news/world/coronavirus-pandemic-crisis-ww2-united-nations -antonio-guterres-a9440006.html> [Accessed 5 September 2021].

BBC.co.uk. (2020). “Coronavirus: there is plenty of food in the supply chain." [online] Available at: < www.bbc.co.uk/news/av/uk-51989833> [Accessed 5 September 2021].

Bentall, R., et al. (2021). Pandemic buying: Testing a psychological model of over-purchasing and panic buying using data from the United Kingdom and the Republic of Ireland during the early phase of the COVID-19 pandemic. PLOS ONE, 16(1), p.e0246339.

Carvalho, H., Duarte, S., Machado, V. C. (2011). Lean, agile, resilient and green: Divergencies and synergies. International Journal of Lean Six Sigma, 2(2), 151-179.

Charron, R., Harrington, H. J., Voehl, F., and Wiggin, H. (2014). The Lean Management Systems Handbook. Productivity Press, OR.

Choi, T. (2021). Fighting against COVID-19: what operations research can help and the sense-and-respond framework. Annals of Operations Research.

Cranfield, J. (2020). Framing consumer food demand responses in a viral pandemic. Canadian Journal of Agricultural Economics/Revue canadienne d'agroeconomie, 68(2), pp. 151-156.

Davey, J. (2021). Britain's supermarkets wrestle with coronavirus demand conundrum. [online] U.S. Available at: 
$<$ https://www.reuters.com/article/us-health-coronavirus-britain-supermarke-idUKKBN21P0GI> [Accessed 5 September 2021].

de Paulo Farias, D. and dos Santos Gomes, M. (2020). COVID-19 outbreak: What should be done to avoid food shortages?. Trends in Food Science \& Technology, 102, pp. 291-292.

Deaton, B. and Deaton, B. (2020). Food security and Canada's agricultural system challenged by COVID-19. Canadian Journal of Agricultural Economics/Revue canadienne d'agroeconomie, 68(2), pp. 143-149.

Depoux, A., Martin, S., Karafillakis, E., Preet, R., Wilder-Smith, A., and Larson, H. (2020). The pandemic of social media panic travels faster than the COVID-19 outbreak. Journal of Travel Medicine, 27(3).

Do, Q., Mishra, N., Wulandhari, N., Ramudhin, A., Sivarajah, U., and Milligan, G. (2021). Supply chain agility responding to unprecedented changes: empirical evidence from the UK food supply chain during COVID-19 crisis. Supply Chain Management: An International Journal, 26(6), pp. 737-752.

Doherty, M. (2016). Through the Looking Glass: Brexit, Free Movement and the Future. King's Law Journal, 27(3), pp. 375-386.

Doornik, J., Castle, J., and Hendry, D. (2020). Short-term forecasting of the coronavirus pandemic. International Journal of Forecasting.

Elluru, S., Gupta, H., Kaur, H., and Singh, S. (2017). Disaster resilient proactive and reactive procurement models for humanitarian supply chain. Production Planning \& Control, pp. 1-14.

Feroze, N. (2020). Forecasting the patterns of COVID-19 and causal impacts of lockdown in top five affected countries using Bayesian Structural Time Series Models. Chaos, Solitons \& Fractals, 140, p. 110196.

Fiksel, J., Polyviou, M., Croxton, K. L., and Petit, T. J. (2015). From risk to resilience: learning to deal with disruption. MIT Sloan Management Review, 56(2), pp. 79-86.

Ft.com. (2020). GSK and Sanofi team up on Covid-19 vaccine. [online] Available at: $<$ https://www.ft.com/content/c67a3dff-558d-42bb-95a6-36e55ac23639> [Accessed 5 September 2021].

Garnett, P., Doherty, B., and Heron, T. (2020). Vulnerability of the United Kingdom's food supply chains exposed by COVID-19. Nature Food, 1(6), pp. 315-318.

GOV.UK. (2021a). Food Statistics in your pocket: Global and UK supply. [online] Available at: <https://www.gov.uk/government/statistics/food-statistics-pocketbook/food-statistics-in-your-pocket-global-and-uksupply\#:\%E2\%88\%BC:text=Based\%20on\%20the\%20farm\%2Dgate,food\%20consumed\%20in\%20the\%20UK> [Accessed 5 September 2021].

Gov.uk. (2021b). Deaths. [online] Available at: <https://coronavirus.data.gov.uk/details/deaths?area Type=nation\&areaName=England $>$ [Accessed 6 September 2021].

Guan, D., Wang, D., Hallegatte, S., Davis, S., Huo, J., Li, S., Bai, Y., Lei, T., Xue, Q., Coffman, D., Cheng, D., Chen, P., Liang, X., Xu, B., Lu, X., Wang, S., Hubacek, K., and Gong, P. (2020). Global supply-chain effects of COVID-19 control measures. Nature Human Behaviour, 4(6), pp. 577-587.

Gunessee, S. and Subramanian, N. (2020). Ambiguity and its coping mechanisms in supply chains lessons from the Covid-19 pandemic and natural disasters. International Journal of Operations \& Production Management, 40(7/8), pp. 1201-1223.

H. L. Lee, V. Padmanabhan, S. Whang. (1997). The bullwhip effect in supply chains. Sloan Management Review, 38(3), pp. 93-102.

Hendry, L., Stevenson, M., MacBryde, J., Ball, P., Sayed, M., and Liu, L. (2019). Local food supply chain resilience to constitutional change: the Brexit effect. International Journal of Operations \& Production Management, 39(3), pp. 429-453.

Hobbs, J. (2020). Food supply chains during the COVID9 pandemic. Canadian Journal of Agricultural Economics/Revue canadienne d'agroeconomie, 68(2), pp. 171-176.

Islam, T., Pitafi, A., Arya, V., Wang, Y., Akhtar, N., Mubarik, S., and Xiaobei, L. (2021). Panic buying in the COVID-19 pandemic: A multi-country examination. Journal of Retailing and Consumer Services, 59, p. 102357.

Ivanov, D. and Dolgui, A. (2018). Low-Certainty-Need (LCN) supply chains: a new perspective in managing disruption 
risks and resilience. International Journal of Production Research, 57(15-16), pp. 5119-5136.

Kumar, Pavan, et al. (2020). Forecasting the dynamics of COVID-19 Pandemic in Top 15 countries in April 2020: ARIMA Model with Machine Learning Approach. medRxiv: n. pag.

Lang, T. and McKee, M. (2018). Brexit poses serious threats to the availability and affordability of food in the United Kingdom. Journal of Public Health, 40(4), pp. e608-e610.

Lee, H. L., Padmanabhan, V., Whang, S. (2000). The value of information sharing in a two-level supply chain. Management Science, 46(2000), pp. 626-643

Leng, H. K. (2021). The COVID-19 Pandemic and Its Impact on Grocery Retailing: A Singapore Case Study. In: Lee, J., Han, S. H. (eds.), The Future of Service Post-COVID-19 Pandemic, Volume 2. The ICT and Evolution of Work. Springer, Singapore.

Leung, J., Chung, J., Tisdale, C., Chiu, V., Lim, C., and Chan, G. (2021). Anxiety and Panic Buying Behavior during COVID-19 Pandemic-A Qualitative Analysis of Toilet Paper Hoarding Contents on Twitter. International Journal of Environmental Research and Public Health, 18(3), p. 1127.

Liu, H., Chu, H., Huang, Q., and Chen, X. (2016). Enhancing the flow experience of consumers in China through interpersonal interaction in social commerce. Computers in Human Behavior, 58, pp. 306-314.

Luqman, A., Masood, A., Weng, Q., Ali, A., and Rasheed, M. (2020). Linking Excessive SNS Use, Technological Friction, Strain, and Discontinuance: The Moderating Role of Guilt. Information Systems Management, 37(2), pp. 94-112.

Matopoulos, A., Didonet, S., Tsanasidis, V., and Fearne, A. (2019). The role of perceived justice in buyer-supplier relationships in times of economic crisis. Journal of Purchasing and Supply Management, 25(4), p. 100554.

Mazurek, J., Perez, C., and García, C. (2020). Forecasting the number of COVID-19 cases and deaths in the World, UK, Russia and Turkey by the Gompertz curve. 10.13140/RG.2.2.32701.61925.

McCarthy, T. and Golicic, S. (2002). Implementing collaborative forecasting to improve supply chain performance. International Journal of Physical Distribution \& Logistics Management, 32(6), pp. 431-454.

Morgan, B. (2020). Dark Stores Are The Future of Post-Pandemic Retail. [online] Forbes. Available at: $<$ https://www.forbes.com/sites/blakemorgan/2020/04/25/dark-stores-are-the-future-of-post-pandemic-retail/?sh=48d 0ccc37826> [Accessed 6 September 2021].

Nabi, K. (2020). Forecasting COVID-19 pandemic: A data-driven analysis. Chaos, Solitons \& Fractals, 139, p. 110046.

Nandi, S., Sarkis, J., Hervani, A., and Helms, M. (2021). Redesigning Supply Chains using Blockchain-Enabled Circular Economy and COVID-19 Experiences. Sustainable Production and Consumption, 27, pp. 10-22.

Nikolopoulos, K. (2021). We need to talk about intermittent demand forecasting. European Journal of Operational Research, 291(2), pp. 549-559.

Nikolopoulos, K., Punia, S., Schäfers, A., Tsinopoulos, C., and Vasilakis, C. (2021). Forecasting and planning during a pandemic: COVID-19 growth rates, supply chain disruptions, and governmental decisions. European Journal of Operational Research, 290(1), pp. 99-115.

Ons.gov.uk. (2021). Coronavirus (COVID-19) Infection Survey technical article-Office for National Statistics. [online] Available at: <https://www.ons.gov.uk/peoplepopulationandcommunity/healthandsocialcare/conditionsanddiseases/ articles/coronaviruscovid19infectionsurveytechnicalarticle/wavesandlagsofcovid19inenglandjune2021> [Accessed 5 September 2021].

Petropoulos, F. and Makridakis, S. (2020). Forecasting the novel coronavirus COVID-19. PLOS ONE, 15(3), p.e0231236.

Queiroz, M., Ivanov, D., Dolgui, A., and Fosso Wamba, S. (2020). Impacts of epidemic outbreaks on supply chains: mapping a research agenda amid the COVID-19 pandemic through a structured literature review. Annals of Operations Research.

Reiley, L. (2020). The industry says we have enough food. Here's why some store shelves are empty anyway. [online] The Washington Post. Available at: <https://www.washingtonpost.com/business/2020/04/14/grocerystores-empty-shelves-shortage/> [Accessed 5 September 2021].

Russell, H. (2021). COVID-19: It's been a year since cases were reported in the UK. [online] Sky News. Available at: 
$<$ https://news.sky.com/story/covid-19-its-been-a-year-since-cases-were-reported-in-the-uk-12201509> [Accessed 5 September 2021].

Saarinen, L., Loikkanen, L., Tanskanen, K., Kaipia, R., Takkunen, S., Holmström, J. (2020). Agile planning: Avoiding disaster in the grocery supply chain during the COVID-19 crisis. Aalto University School of Science. Alto University School of Business.

Schmidt, W. and Ananth Raman. (2012). "When Supply-Chain Disruptions Matter.” Harvard Business School Working Paper, No. 13-006, July 2012.

Schorfheide, F. and Song, D. (2020). Real-Time Forecasting with a (Standard) Mixed-Frequency VAR During a Pandemic. SSRN Electronic Journal.

Shekarian, M., Reza Nooraie, S., and Parast, M. (2020). An examination of the impact of flexibility and agility on mitigating supply chain disruptions. International Journal of Production Economics, 220, p. 107438.

Shih, W. (2020). Global Supply Chains in a Post-Pandemic World. [online] Harvard Business Review. Available at: $<$ https://hbr.org/2020/09/global-supply-chains-in-a-post-pandemic-world> [Accessed 6 September 2021].

Speare-Cole, R. (2020). Tesco to hire 20,000 staff as demand surges amid Covid-19 crisis. [online] Standard.co.uk. Available at: <https://www.standard.co.uk/news/uk/tesco-jobs-20000-coronavirus-covid19-demandsurge-shopping-a4393636.html $>$ [Accessed 5 September 2021].

Spithourakis, G., Petropoulos, F., Babai, M., Nikolopoulos, K., and Assimakopoulos, V. (2011). Improving the Performance of Popular Supply Chain Forecasting Techniques. Supply Chain Forum: An International Journal, 12(4), pp. 16-25.

Sujath, R., Chatterjee, J., and Hassanien, A. (2020). A machine learning forecasting model for COVID-19 pandemic in India. Stochastic Environmental Research and Risk Assessment, 34(7), pp. 959-972.

Syntetos, A., Babai, Z., Boylan, J., Kolassa, S., and Nikolopoulos, K. (2016). Supply chain forecasting: Theory, practice, their gap and the future. European Journal of Operational Research, 252(1), pp. 1-26.

Taleb, N. N. (2007). The Black Swan: The impact of the highly improbable. Penguin Books Ltd, London (2007).

Tsao, Y., Raj, P., and Yu, V. (2019). Product substitution in different weights and brands considering customer segmentation and panic buying behavior. Industrial Marketing Management, 77, pp. 209-220.

Watson, A. (2020). Media usage during COVID-19 by country. WWW Document. Statista. Available at: < https://www.statista.com/statistics/1106498/home-media-consumption-coronavirus-worldwide-by-country/> 2020. [Accessed 5 September 2021].

Who.int. (2020). WHO Director-General's opening remarks at the media briefing on COVID-19 - 11 March 2020. [online] Available at: <https://www.who.int/director-general/speeches/detail/who-director-general-s-opening -remarks-at-the-media-briefing-on-covid-19---11-march-2020> [Accessed 5 September 2021].

Wu, Y., Xin, L., Li, D., Yu, J., and Guo, J. (2021). How does scarcity promotion lead to impulse purchase in the online market? A field experiment. Information \& Management, 58(1), p. 103283.

Zarei, M., Fakhrzad, M. B., and Jamali Paghaleh, M. (2011). Food supply chain leanness using a developed QFD model. Journal of Food Engineering, 102(1), pp. 25-33.

Zhang, S., Wang, S., Yuan, L., Liu, X., and Gong, B. (2020). The impact of epidemics on agricultural production and forecast of COVID-19. China Agricultural Economic Review, 12(3), pp. 409-425.

Zhu, G., Chou, M., and Tsai, C. (2020). Lessons Learned from the COVID-19 Pandemic Exposing the Shortcomings of Current Supply Chain Operations: A Long-Term Prescriptive Offering. Sustainability, 12(14), p. 5858. 


\section{Appendix A}

Table 1. Results of the thematic analysis

\begin{tabular}{|c|c|c|}
\hline Theme & Quote(s) From Interviewee(s) & Context \& Interpretation \\
\hline \multirow[t]{2}{*}{$\begin{array}{l}\text { 1: Changes in the } \\
\text { buying behaviours } \\
\text { of consumers }\end{array}$} & $\begin{array}{l}\text { B: "Food to go and meal deals are experiencing an increase again } \\
\text { now that customers are returning. Beforehand, when offices were } \\
\text { shut, that was one of the biggest areas where we'd drop sales." } \\
\text { F: "Things like on the go cereal bars for example where people } \\
\text { would eat breakfast on the way to work, like a cereal bar on the train } \\
\text { remained low throughout. So, since there were less trains and less } \\
\text { people in offices, you can have a box of cereal or make beans on } \\
\text { toast or eggs or whatever." }\end{array}$ & $\begin{array}{l}\text { Demand for quick snacks and } \\
\text { ready-made meals stayed low even } \\
\text { after the first lockdown due to em- } \\
\text { ployees working from home. }\end{array}$ \\
\hline & $\begin{array}{l}\text { I: "If you take our sales profile this time last year, it changed com- } \\
\text { pletely because of the pandemic. We had stronger sales on Monday, } \\
\text { Tuesday, Wednesday, Thursday, and Friday, Saturday and Sunday } \\
\text { were very quiet. Whereas normally it's the other way around. Our } \\
\text { busiest day of the week is Friday and Saturday." }\end{array}$ & $\begin{array}{l}\text { In the pandemic, consumers started } \\
\text { to shop more on weekdays than on } \\
\text { the weekends. }\end{array}$ \\
\hline \multirow{6}{*}{$\begin{array}{l}\text { 2: Supply Side } \\
\text { Issues }\end{array}$} & $\begin{array}{l}\text { H: "There’s challenges around drivers, part of it is Brexit, but we’re } \\
\text { offering incentives for drivers too for signing up, like a } £ 500 \text { loan } \\
\text { just to do your training." }\end{array}$ & \multirow{2}{*}{$\begin{array}{l}\text { 8/10 interviewees mentioned recent } \\
\text { problems around drivers. Particularly } \\
\text { due to Brexit a lot of drivers from EU } \\
\text { have left the UK which has caused } \\
\text { some delays in deliveries. }\end{array}$} \\
\hline & $\begin{array}{l}\text { E: "I mean we're in a shortage of drivers at the minute. So probably } \\
\text { the supply chain they're recognizing our drivers and making sure } \\
\text { that we are offering them grand benefits as a company, which leads } \\
\text { to more pay and recognition. As a company we are maintaining and } \\
\text { keeping those drivers because they are more central to our business. }\end{array}$ & \\
\hline & $\begin{array}{l}\text { E: "We're delivering it by rail because that reduces our timeframe } \\
\text { by a quarter. It takes only } 3 \text { days to transport products from Spain } \\
\text { compared to road and that's how we're delivering fresher products } \\
\text { for our customers." }\end{array}$ & $\begin{array}{l}\text { Categorized as a delivery issue again } \\
\text { like the above. Faster means of } \\
\text { transportation used (trains instead of } \\
\text { lorries and buses) to improve delive- } \\
\text { ries. }\end{array}$ \\
\hline & $\begin{array}{l}\text { E: "We've actually had it recently with a honey product that we'd } \\
\text { use alternative products. So, we would rather than using Rowse } \\
\text { honey get Hilltop honey and the supply of that was from a different } \\
\text { supplier, so we've had loads of different suppliers." }\end{array}$ & \multirow{2}{*}{$\begin{array}{l}\text { A supply side issue again but specif- } \\
\text { ically more to do with sourcing. Al- } \\
\text { ternative sources/ suppliers were } \\
\text { approached during the pandemic } \\
\text { when supply from first choice sup- } \\
\text { plier was unreliable. }\end{array}$} \\
\hline & $\begin{array}{l}\text { C: "So being able to have alternate sources for things and being able } \\
\text { to have a greater pool of individuals that we could get stuff from } \\
\text { was certainly quite practical." }\end{array}$ & \\
\hline & $\begin{array}{l}\text { I: "I'd actually say in a way that the supply challenges were probably } \\
\text { more severe than the demand disruptions because one of the things } \\
\text { was there wasn't a shortage of products or ingredients for the prod- } \\
\text { ucts the customers wanted, we just couldn't physically get it to them } \\
\text { in time. }\end{array}$ & $\begin{array}{l}\text { Comparison of demand vs supply } \\
\text { disruptions saying supply side were } \\
\text { worse. }\end{array}$ \\
\hline \multirow{3}{*}{$\begin{array}{l}\text { 3: Reducing costs } \\
\text { and range }\end{array}$} & $\begin{array}{l}\text { E: "I wouldn't change our distribution network because it's going to } \\
\text { add costs to our business operations. We need to be efficient and } \\
\text { have a low-cost element to it. With the grocery sector as a whole, } \\
\text { the idea now is cutting costs, its very price competitive at the mo- } \\
\text { ment." } \\
\text { D: "So, there is an argument we had and I am sure its being had } \\
\text { everywhere about do we maybe hold a bit more stock so we can deal } \\
\text { with these crazy fluctuations? But that's just so much cash that you } \\
\text { don't end up looking at. It's not something you want to do, so it's a } \\
\text { huge decision to make." }\end{array}$ & $\begin{array}{l}\text { Clear focus on cutting down costs in } \\
\text { the long run and streamlining opera- } \\
\text { tions. }\end{array}$ \\
\hline & $\begin{array}{l}\text { F: "I think one of the biggest things is around the ranges that we } \\
\text { carry. In order to get the most efficiency out of factories you need to } \\
\text { simplify the product offering that you're doing. So one thing we } \\
\text { probably look at differently in the future is start to trim off the peri- } \\
\text { phery of the range." }\end{array}$ & \multirow{2}{*}{$\begin{array}{l}\text { Similar to cutting costs, trimming } \\
\text { down ranges also streamlines opera- } \\
\text { tions making them more efficient and } \\
\text { supply more reliable for key items. }\end{array}$} \\
\hline & $\begin{array}{l}\text { I- "I suppose the whole pandemic has made us focus more on the } \\
\text { breadth and depth of our ranges that we carry. So one of the ways } \\
\text { that we can improve availability bizarrely is actually by reducing the } \\
\text { amount of range that we take. So, it's looking at which bits of the }\end{array}$ & \\
\hline
\end{tabular}




\begin{tabular}{|c|c|c|}
\hline & $\begin{array}{l}\text { range do you really need. } \\
\text { I: "So it's how you plan on the supplies, the supply side that's key } \\
\text { and this is where it comes back to participants, working with them } \\
\text { on which are the products that we definitely need to prioritize. You } \\
\text { have to prioritize the range; you have to prioritize which products } \\
\text { you want, and you know if there's only so many hundreds of lorries } \\
\text { that you can get up from Spain, you have to prioritize the ingredients } \\
\text { or the best-selling products in order to bring that up. That's probably } \\
\text { the biggest change you'd be doing." }\end{array}$ & \\
\hline & $\begin{array}{l}\text { D: "We were always going to grow online shopping but now that's } \\
\text { been expedited, we're setting up these people-less warehouses, dark } \\
\text { stores we call them. So, we can service people faster in terms of } \\
\text { online shopping so they don't have to do that picking in-stores." }\end{array}$ & $\begin{array}{l}\text { Considerations around dark stores as } \\
\text { a way to improve customer service } \\
\text { after the rise in online shopping dur- } \\
\text { ing the pandemic. }\end{array}$ \\
\hline $\begin{array}{l}\text { 4: New Develop- } \\
\text { ments }\end{array}$ & $\begin{array}{l}\text { I: "One of the things that we all do with our suppliers is we have } \\
\text { started to have more regular contact now with them so that they } \\
\text { don't necessarily get to change any orders that come through to } \\
\text { them. But we will work with a number of our key strategic suppliers } \\
\text { to talk about the forecast and share with them our thinking so that } \\
\text { they are first of all a lot closer to it and they understand the thinking } \\
\text { behind it so that they can influence. So, working more collabora- } \\
\text { tively with our suppliers it's probably the key thing to do first of } \\
\text { all." }\end{array}$ & $\begin{array}{l}\text { Increased collaboration and informa- } \\
\text { tion sharing with suppliers to work } \\
\text { towards mutual goals like getting the } \\
\text { right quantities delivered often. }\end{array}$ \\
\hline
\end{tabular}

Table 2. Additional quotes of interviewees according to the themes identified using thematic analysis

\begin{tabular}{|c|c|c|}
\hline Theme & Quote(s) From Interviewee(s) & Context \& Interpretation \\
\hline \multirow[b]{2}{*}{$\begin{array}{l}\text { 1: Changes in the } \\
\text { buying behaviours } \\
\text { of consumers }\end{array}$} & $\begin{array}{l}\text { A: "Ready meals, soft drinks and confectionery. We haven't picked } \\
\text { up in customers at all, we haven't. We're still low on them coming } \\
\text { in because obviously we used to have all the office workers around } \\
\text { and all the students around.” }\end{array}$ & \multirow{2}{*}{$\begin{array}{l}\text { Demand for quick snacks and } \\
\text { ready-made meals stayed low even } \\
\text { after the first lockdown due to em- } \\
\text { ployees working from home. }\end{array}$} \\
\hline & $\begin{array}{l}\text { I: "I think confectionery from what I remember, they didn't have a } \\
\text { particularly strong year because you think a lot of people will buy } \\
\text { confectionery when they're out and about that they might have a } \\
\text { chocolate bar with their lunch or they might buy it on the way back } \\
\text { from work. But if customers weren't out and about driving places or } \\
\text { going to work so demand fell away for those areas." }\end{array}$ & \\
\hline \multirow{5}{*}{$\begin{array}{l}\text { 2: } \quad \text { Supply Side } \\
\text { Issues }\end{array}$} & $\begin{array}{l}\text { A: "The distributors said that there are not enough delivery drivers } \\
\text { at the minute. Due to covid, the foreign people who they employ, } \\
\text { they gave them a big pay out to be available through covid but } \\
\text { they've gone back home now, so we're running shortages on delive- } \\
\text { ries. It's everywhere, it's pubs everything, so we've got the supplies } \\
\text { but we haven't got the delivery drivers." }\end{array}$ & \multirow{5}{*}{$\begin{array}{l}\text { 8/10 interviewees mentioned recent } \\
\text { problems around drivers. Particularly } \\
\text { due to Brexit a lot of drivers from } \\
\text { EU have left the UK which has } \\
\text { caused some delays in deliveries. }\end{array}$} \\
\hline & $\begin{array}{l}\text { B: “And sometimes you don't know that you're not going to get a } \\
\text { delivery because they don't turn up due to driver shortage.” }\end{array}$ & \\
\hline & $\begin{array}{l}\text { C: "We're at a stage now where they're having to move around } \\
\text { frozen deliveries because of a lack of availability of drivers \& that } \\
\text { kind of thing." }\end{array}$ & \\
\hline & $\begin{array}{l}\text { F: "Obviously we don't have the same kind of labour we used to, } \\
\text { especially drivers." }\end{array}$ & \\
\hline & $\begin{array}{l}\text { I: "Yeah and I know people joke about Brexit a lot but that certainly } \\
\text { didn't help the situation because that's added to the shortage of driv- } \\
\text { ers......." }\end{array}$ & \\
\hline $\begin{array}{l}\text { 3: Reducing costs } \\
\text { and range }\end{array}$ & $\begin{array}{l}\text { I: "The move has been towards low-cost products. They have looked } \\
\text { further and further afield and so that's not actually an easy one for } \\
\text { lots of the retailers to turn on." }\end{array}$ & $\begin{array}{l}\text { Clear focus on cutting down costs in } \\
\text { the long run and streamlining opera- } \\
\text { tions. }\end{array}$ \\
\hline $\begin{array}{l}\text { 4: New Develop- } \\
\text { ments }\end{array}$ & $\begin{array}{l}\text { J: "So we're talking to everybody because without that collaboration } \\
\text { you're all going to be working off different numbers so within this } \\
\text { organization everybody is trying to work off the same number. } \\
\text { Therefore, the conversation that's had is deciding on what number } \\
\text { we're all going to work to that will be different by business unit } \\
\text { we'll have different numbers but yeah it's a collaborative thing." }\end{array}$ & $\begin{array}{l}\text { Increased collaboration with suppli- } \\
\text { ers to work towards mutual goals } \\
\text { like getting the right quantities deli- } \\
\text { vered often. }\end{array}$ \\
\hline
\end{tabular}

